\title{
NOVES TENDÈNCIES DIDÀCTIQUES EN L'ENSENYAMENT DEL LLATÍ I LA CULTURA CLÀSSICA: LES TROBADES D'ALUMNES DE LLATÍ A 4T D'ESO
}

\author{
LiNA ViLAMitjanA PUJOL \\ Institut Montgrí (Torroella de Montgrí) \\ lina.vilamitjana@gmail.com \\ MONTSERRAT FIOL SANTALÓ \\ Institut Illa de Rodes (Roses) \\ mfiol2@xtec.cat
}

RESUM

Les trobades d'alumnes de Llatí de 4t d'ESO, organitzades per l'Equip ICE Dolors Condom de Cultura Clàssica, pretenen acostar l'alumnat al món clàssic a través d'una jornada ludicodidàctica. Aquestes trobades es realitzen cada any en un lloc diferent i en una zona de les comarques gironines on hi ha restes arqueològiques romanes: Empúries, Roses, Girona, Caldes de Malavella i, fins i tot, la via romana del Capsacosta; així l'alumnat pot veure in situ les restes arqueològiques i al mateix temps realitzar activitats lúdiques i d'aprenentatge sobre el món clàssic. Per tal de poder dur a terme aquesta activitat necessitem la implicació de les diferents entitats de la zona, en primer lloc els ajuntaments, però també els museus, els jaciments arqueològics, la Universitat de Girona, el Bisbat de Girona i organitzacions culturals com els manaies o les colles geganteres. Però el que engresca més l'alumnat és el fet de conèixer altres joves com ells i realitzar les activitats conjuntament, sobretot les més lúdiques i les relacionades amb les noves tecnologies, que els són més familiars. La intenció és que s'interessin i apreciïn la influència del món clàssic en el nostre entorn més pròxim.

PARAULES CLAU: trobades d'alumnes, llatí, ESO, restes romanes.

\section{NEW DIDACTIC TRENDS IN THE TEACHING OF LATIN AND CLASSICAL CULTURE: THE MEETINGS OF $4^{\mathrm{TH}}$ ESO LATIN STUDENTS}

\section{ABSTRACT}

The meetings of $4^{\text {th }}$ ESO (compulsory secondary school) Latin students, organised by the ICE (Institute of Education Sciences) team of Classical Culture Dolors Condom, aim to engage students in the study of the classical world through a festive all-day gathering. These meetings are held every year in a different spot in the province of Girona where there are still some Roman archaeological remains, namely Empúries, Roses, Girona, Caldes de Malavella and even the Roman road of Capsacosta. Students can experience in situ the archaeological site they are visiting while doing recreation activities which will help them learn about the classical world. To carry out these meetings, it is essential to involve the entities from the area, mainly town councils, but also museums, archaeological sites, the University of Girona, the Bishopric of Girona and other cultural organisations. However, the most exciting thing for students is to get in contact with other youths and have the chance to share educational activities, especially those related to ICT. Our goal is to make them become interested in the classical world and, at the same time, appreciate its legacy in their closest surroundings.

KEYWORDS: student meetings, Latin, secondary education, Roman remains. 
L'equip de Cultura Clàssica de l'ICE Josep Pallach de la Universitat de Girona hem preparat, de l'any 2009 ençà, set trobades d'alumnes de Llatí de 4t d'ESO a diferents indrets d'interès arqueològic de les comarques gironines, a partir de la idea proposada per la professora Anna Saurí de l'Institut El Pedró de l'Escala, que malauradament ens va deixar a causa d'un accident l'estiu del 2015. La ubicació de la trobada canvia en cada nova edició, sempre procurant que siguin espais adequats a la logística de l'organització.

L'Equip ICE de Cultura Clàssica -que avui compta més de vint membresva néixer l'any 2010 per la necessitat de crear un espai d'intercanvi, reflexió i col-laboració entre els docents de clàssiques de les comarques gironines. Any rere any hem anat augmentant el nombre de participants i també hem anat ampliant els nostres objectius i les nostres activitats per donar més importància a la difusió del món clàssic. L'equip ha pres el nom de la professora gironina Dolors Condom en honor del seu mestratge, atès que va fer una gran tasca en l'estudi i la difusió dels estudis clàssics i en la transmissió a les aules dels valors del món grecoromà.

El curs 2017-2018 la trobada d'alumnes de Llatí ha arribat a la seva VIII edició i hem visitat les restes romanes de les termes de Caldes de Malavella (fig. 1). El curs 2018-2019, si tot va bé, farem la IX trobada al jaciment grecoromà d'Empúries; serà la tercera vegada que hi anem i esperem que en aquesta ocasió vagi tan bé com en les altres.

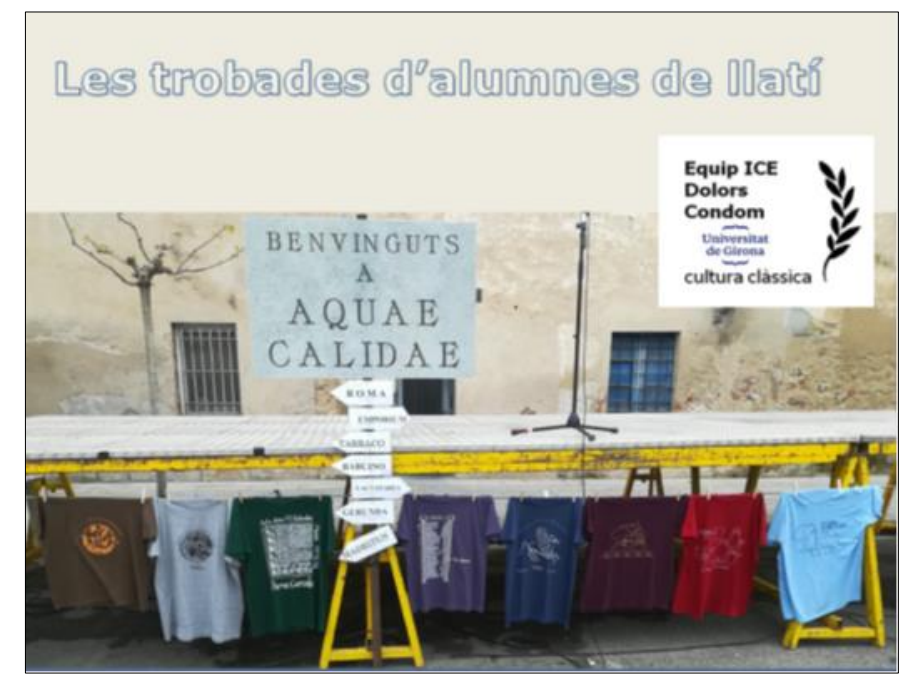

Fig. 1. Escenari de la VIII trobada a Caldes de Malavella.

El principal objectiu de la trobada és donar a conèixer als nostres alumnes les restes grecoromanes de les comarques gironines i que valorin la petjada de la civilització clàssica en el nostre país. Els proposem treballar en equip enmig d'un ambient lúdic i vivencial, per tal que puguin relacionar-se entre ells $i$, al mateix temps, estimular el seu interès pel món clàssic.

Pretenem que alumnat adquireixi els coneixements curriculars de la matèria de manera lúdica a partir de tallers, conferències, obres de teatre i les 
diferents eines que ens proporcionen les noves tecnologies (Kahoot!, formularis Google, fotografies compartides...) mitjançant les aplicacions del mòbil.

També procurem interactuar amb aquelles entitats culturals i tradicionals de la zona que tracten algun aspecte de la cultura clàssica, com els Manaies de Girona, els Gegants Romans de Caldes de Malavella o els de la Vall de Bianya (fig. 2).

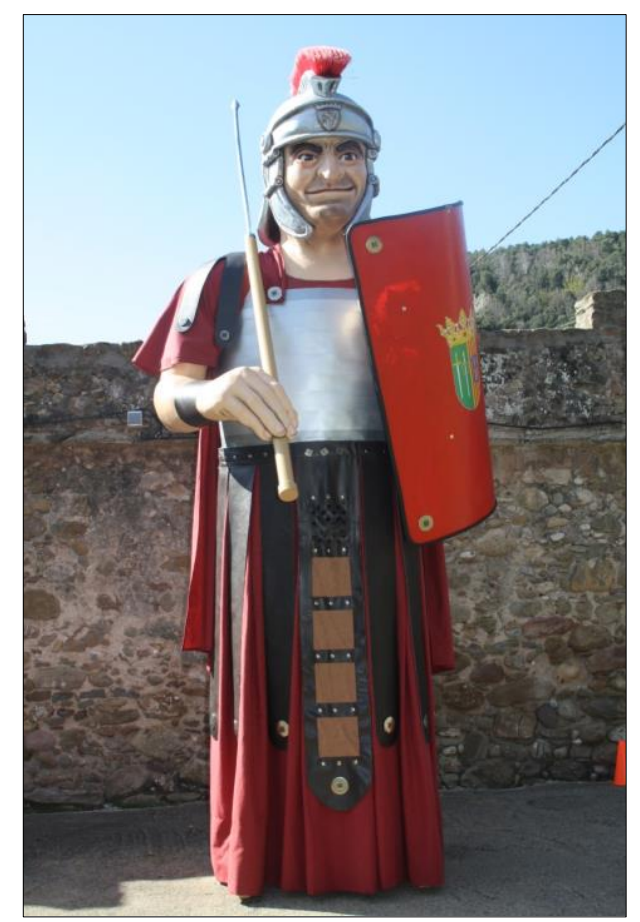

Fig. 2. Gegant romà de la Vall de Bianya.

I finalment, amb aquesta trobada, volem reivindicar la necessitat de preservar l'oferta de llengües clàssiques en els nostres instituts, en el benentès que aquestes són fonamentals en la formació integral dels nostres alumnes i constitueixen un dels pilars bàsics de la civilització occidental.

Pel que fa a la preparació de la trobada, hem de tenir en compte diversos aspectes. En primer lloc cerquem el suport de les diferents entitats de la zona on es fa la trobada. Contactem amb els ajuntaments o els jaciments arqueològics i els demanem els permisos necessaris per utilitzar-ne els espais, el material que ens cal i sovint l'ajuda dels seus treballadors per fer tot el muntatge. També demanem la col-laboració dels diferents museus, del Bisbat, de la Universitat de Girona, dels camps d'aprenentatge i també de persones i empreses privades de la zona, sempre, és clar, amb el vistiplau del Departament d'Educació. Els instituts veïns també col-laboren en la preparació i sovint disposem de l'ajuda de voluntaris que, juntament amb el professorat participant, fan possible que la trobada es pugui realitzar.

Uns mesos abans de la data de realització de la trobada enviem un formulari d'inscripció a tots els centres de les comarques gironines. En aquest formulari ja hi consta el lloc, la data, l'horari i les activitats que es faran. Els 
centres que hi volen participar s'hi inscriuen i així ja sabem ben aviat el nombre $\mathrm{d}^{\prime}$ alumnes amb què hem de comptar.

Un altre element important de la trobada és la samarreta: cada any n'elaborem una de commemorativa (fig. 3). Tots els participants la portem: els alumnes, els professors, els voluntaris, els alcaldes, els regidors... Procurem que tingui un disseny amb algun element identificador de la zona que visitem, el seu nom en llatí -i, si és possible, també en grec- i finalment la data en llatí. Aquesta samarreta és el record material que s'emportaran tots els alumnes.

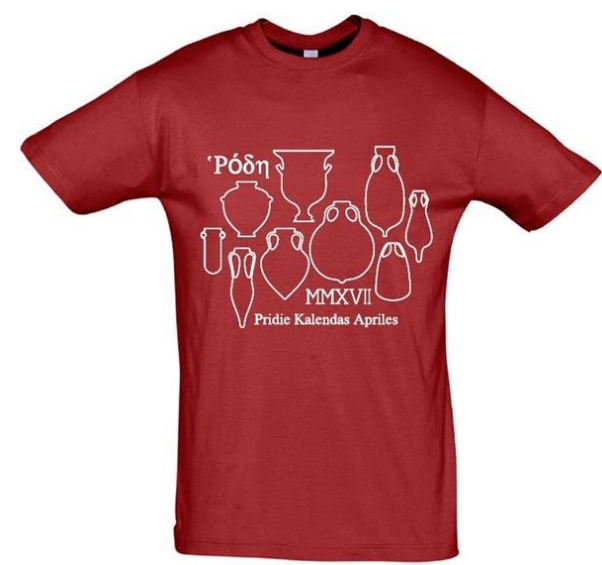

Fig. 3. Samarreta de la VII trobada.

L'equip també prepara els materials didàctics que s'han de treballar prèviament als centres. Aquests materials contenen una àmplia informació històrica sobre la zona i els aspectes rellevants de l'indret que es visita (els jaciments, les vies de comunicació, les termes, l'urbanisme, el comerç, el calendari...). Cada centre participant rep un plec informatiu, un document amb imatges (PowerPoint), el programa de la trobada (fig. 4) i els mapes de la zona.

La trobada comença amb un acte al qual estan convidades les diferents autoritats: els directors de l'Institut de Ciències de l'Educació, del Departament d'Educació, del jaciment arqueològic i l'alcalde de la localitat, que ens donen la benvinguda. Seguidament expliquem el programa de la jornada i donem les instruccions als alumnes.

La jornada consisteix en un seguit d'activitats que els estudiants fan en grups de 10 o 15 alumnes de dos o tres centres diferents. Les activitats han anat canviant al llarg de les trobades: inicialment estaven programades per conèixer la zona (gimcana, conferències, visites guiades) i sempre acabaven amb un prandium; després vam començar a fer-ne de més lúdiques (Kahoot!) combinades amb una gimcana i, darrerament, procurem combinar activitats més participatives (tallers) amb una obra de teatre. Com que el nombre d'alumnes és elevat, planifiquem les activitats en dos torns simultanis.

La trobada finalitza amb un lliurament de premis i un breu discurs de comiat, en el qual hi ha quatre mots en llatí que els alumnes poden comprendre. Finalment cantem tots junts el Gaudeamus per acomiadar la diada. 


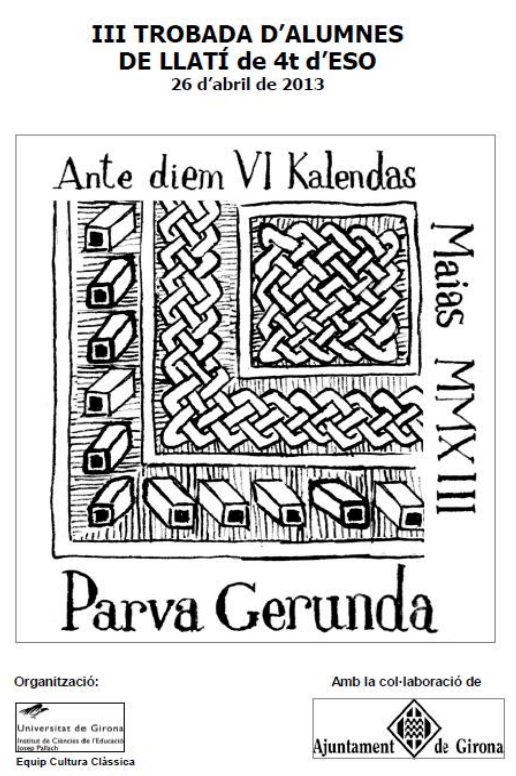

Fig. 4. Programa de la III trobada a Girona.

Després de cada trobada en fem la valoració. S'elabora una enquesta, que es pot respondre de manera individual a partir d'un formulari Google, i s'envia als centres per tal que tots els participants (alumnes, professors i voluntaris) la puguin omplir; a més, cada professor pot fer-la a l'aula amb tot el grup.

A partir dels resultats de l'enquesta hem anat modificant les activitats i fins i tot l'estructura del programa: hem deixat de fer el prandium, sobretot a causa de l'elevat nombre d'alumnes, hem reduï el nombre de tallers, en funció de les preferències dels participants, hem ampliat l'ús de les noves tecnologies i hi hem incorporat les arts escèniques.

Com que el nombre de participants ha anat en augment, hem hagut de limitar l'assistència, de vegades per motius de capacitat i d'altres per la pròpia organització de la trobada.

Valorem molt positivament el fet que alguns centres vinguin de molt lluny i també la fidelitat dels centres participants, alguns dels quals hi han estat presents des de la primera edició.

Després de vuit edicions creiem que la trobada és una activitat consolidada a les comarques gironines, té èxit entre els alumnes i de mica en mica hem anat aconseguint que, de manera lúdica, prenguin consciència del patrimoni que tenim al nostre territori. També hem pogut constatar que ha anat creixent l'interès de la trobada entre els mitjans de comunicació: habitualment apareix informació de l'activitat a les emissores de ràdio i a les televisions.

Per acabar, us presentem una graella on podeu veure les diferents edicions de la trobada, els alumnes i centres participants i les activitats que hi hem dut a terme (fig. 5). 


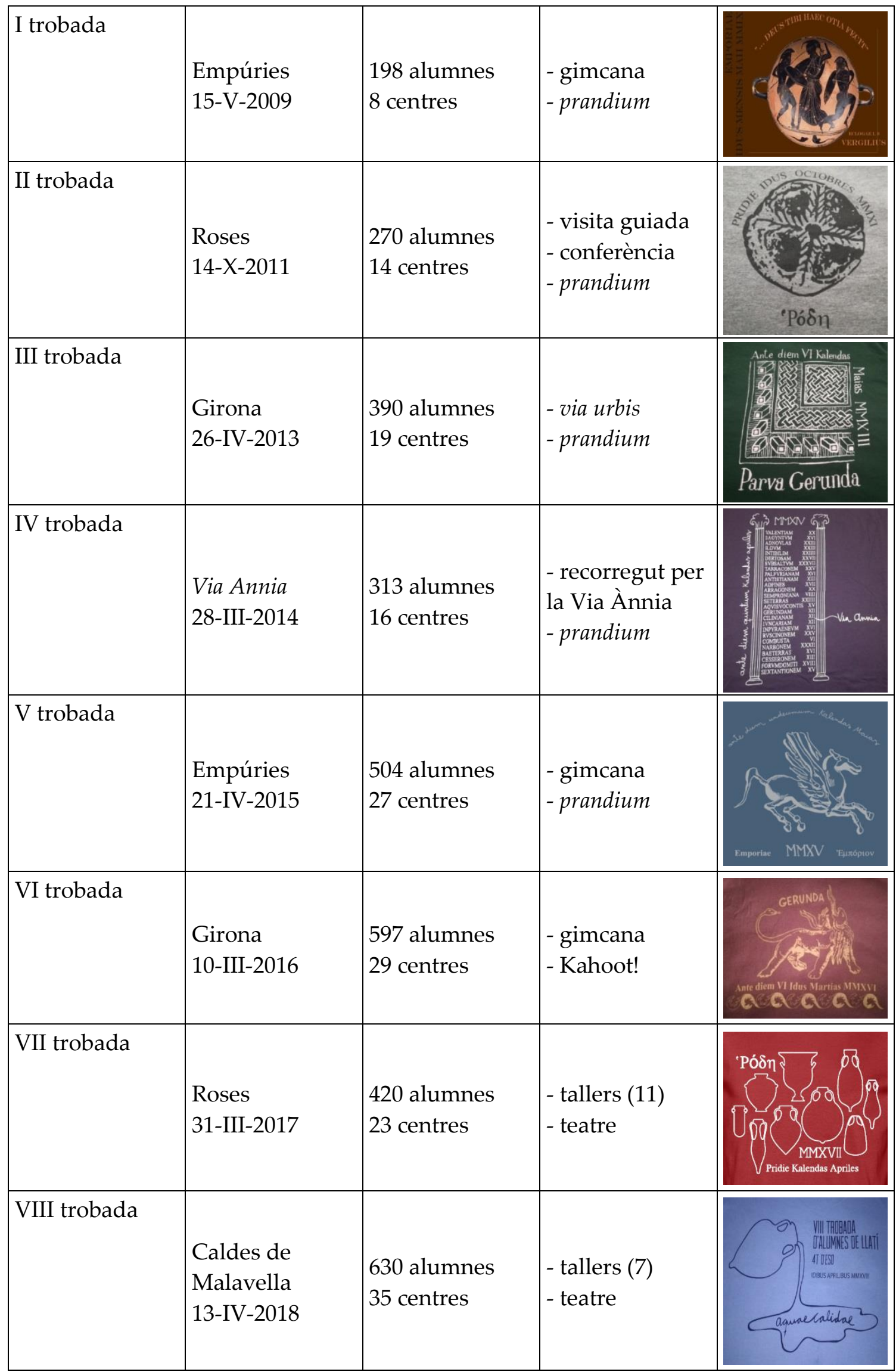

Fig. 5. Graella de les diferents trobades. 